\title{
I Fought the Law: Transgressive Play and The Implied Player
}

\author{
Espen Aarseth \\ Center for Computer Games Research \\ IT University of Copenhagen, Denmark \\ aarseth at itu $\mathrm{dk}$
}

\begin{abstract}
This paper is an attempt to understand Game Studies through the contested notion of the "player" both inside and outside "the game object" - that is the object that game users perceive and respond to when they play. Building on Hans-Georg Gadamer's notion of games as a subject that "masters the players", the paper will go beyond the traditional split between the social sciences' real players and the aesthetics/humanities critical author-as-player, and present a theory of the player and player studies that incorporates the complex tensions between the real, historical player and the game's human components. Since games are both aesthetic and social phenomena, a theory of the player must combine both social and aesthetic perspectives to be successful. The tension between the humanities and the social sciences over who controls the idea of the player can be found mirrored also in the struggle between the player as individual and the "player function" of the game. Transgressive play, the struggle against the game's ideal player, far from being a marginal, romanticized phenomenon, is the core expression of this struggle.
\end{abstract}

\section{Author Keywords}

Implied player, Transgressive play

\section{INTRODUCTION: WHO IS THE PLAYER?}

"...the game masters the players. [...] The real subject of the game $[. .$.$] is not the players but the game itself" -Gadamer,$

Truth and Method, p.106

What is a player? In what sense does a player exist? When does a player exist? Can there be a player, if there is no game? Before there is a game? Clearly, players cannot exist with out a game they are players of. A generic player is an unthinkable, not merely ahistorical, figure. Games, on the other hand, can exist without actual, current players, as material and conceptual game objects ("texts"). While the game-without-a-player is a limited perspective, it does denote a hierarchical relationship: the historical player cannot exist without a game, but the game, at some point in its existence (e.g. before the first playtesting session in a development cycle), can exist without players, and always without one particular, historical player.

The potential player, before becoming an actual player, must receive some instructions, either from the game itself, or from a guide or accompanying material. Thus, the player is created, by these instructions, and by his or her initial learning experience. In many cases, this experience is social, and the player learns from other, more experienced players. But this is far from always the case, especially with singleplayer games. While it is important to acknowledge that even singleplay can be perfectly social (eg. when two players cooperate or in a group discuss the intricacies of a singleplayer game) it is perhaps just as important not to forget the solitary player, exploring by herself, Bartelian-explorer style, and discovering esoteric aspects that socially conformed, player-oriented gamers may never find.

In Truth and Method [4], Hans-Georg Gadamer argues that games are the real subject in play, not the players:

...all playing is a being-played. The attraction of a game, the fascination it exerts, consists precisely in the fact that the game masters the players. [...] Whoever "tries" is in fact the one who is tried. The real subject of the game (this is shown in precisely those experiences where there is only a single player) is not the player but instead the game itself. What holds the player in its spell, draws him into play, and keeps him there is the game itself (106).

By accepting to play, the player subjects herself to the rules and structures of the game and this defines the player: a person subjected to a rule-based system; no longer a complete, free subject with the power to decide what to do next.

At this point, a working definition of game is in order. This is not the place to discuss previous definitions of games, so instead I will simply present my own, which should be relevant for the issue at hand: Games are facilitators that structure player behavior, and whose main purpose is enjoyment. Hence, a theory of games, whether

\section{Situated Play, Proceedings of DiGRA 2007 Conference}

(C) 2007 Authors \& Digital Games Research Association (DiGRA). Personal and educational classroom use of this paper is allowed, commercial use requires specific permission from the author. 
ontological, aesthetic, or socially oriented, must focus on player behavior. This definition is intentionally wide open; it will encompass toy-like games such as The Sims and GTA3 as well as social online worlds (MMOGs) such as Eve and Second Life, and thus serve the goal of the paper, which is to discuss the notion of the player in the broadest possible sense.

\section{THE TWO PLAYERS}

In his recent $\mathrm{PhD}$ dissertation, Jonas Heide Smith [6] gives an excellent overview over the way game research literature has dealt with the player. Smith outlines four main approaches: 1) the susceptible player model (from effects research), the Selective Player Model (from media studies), 3 ) the active player model (from computer game studies) and 4) the Rational player model (from game design and economic game theory). He then goes on to focus his dissertation on the fourth model, which he finds most fruitful. To give Smith the attention he deserves would unfortunately bring us outside the scope of this paper. Instead, a single point will be engaged with here: the notion that Game Studies harbors a dominant player model, the "active player": "actively engaged with the game or gamespace in ways often not prescribed or predicted by the game designers" (p.24). Citing a number of studies, Smith notes that Game Studies researchers seem to prefer the type of player behavior that is active, creative and subversive, and going against the designs of the game makers. Although Smith here carefully avoids overt criticism of the "Active player" perspective as naïve, celebratory, misguided and romantic, such a criticism can easily be made following his observation, especially given the clear bias such a view represents in favor of the statistically marginal subversive or truly innovative play styles. Most players simply follow the directions and play to win, so why put the focus on those few who don't? Are game studies researchers really unaware of what typical players actually do, or are they just bored by it, and look for more colorful examples to liven their writing?

While Smith has pointed to a trend in Game Studies that clearly invites some self-critical rethinking and academic soul-searching, I would here like to argue that innovative, subversive and transgressive play, while perhaps statistically unrepresentative, is nevertheless a crucial aspect of, and the key to understanding all kinds of play and game culture; and therefore one that deserves the (critical) attention we can give it. Also, Smith puts little weight on the fairly visible divide in game studies between "player" studies and "text" studies, that is, the potential conflict between the humanist and the social sciences camp. These two camps, one focused on understanding games through playing them, and one focused on observing actual players, represent two quite separate paradigms in terms of their player perspective, and two that are not always living happily side by side.
On the one hand, there is the critical playertheorist, whose empirical target is the game as an aesthetic object, just like any other (films, music, visual art) but with the added challenge of gameplay. This researcher considers her own playing experience as a valid basis for doing theory, and is interested in the game as a cultural, expressive object. The fact that she is studying an object that at the time of study is a process partly instigated by her, and not necessarily shared by any other player, is seldom a topic for discussion, but bracketed by experience of play.

On the other hand, there is the ethnographic player-observer, whose empirical focus is the other players, their habits, actions, values and relationships. This researcher is careful to extract or neutralize her own experience, to the extent that it is possible. Self-play is here potentially suspect, since it is subjective and quite likely unrepresentative. While her own experience of the game might be used as background information to better understand the observed players, the data samples are a presumably representative and hopefully diverse group of real, historical players.

A tension exists between these two researcher types, caused partly by the lack of realization that the object they study is not the same. For the humanist, the player is a function of the game, a slot in a game machine that can be filled by any rational, critical, informed person - a model reader, in Umberto Eco's terms[3]. For the sociologist or ethnographer, the player is an actual, historical person, or better, persons.

However, there is another tension at work, which is just as important: the methodological divide between formal and informal methods. (In the social sciences, between quantitative and qualitative, and in the humanities, between structuralism/"theory" and close reading). In other words, we can divide the field of gameplay studies in four, along empirical and methodological lines:

\begin{tabular}{|l|l|l|}
\hline & Social sciences & The Humanities \\
\hline Case studies & Field work & $\begin{array}{l}\text { Close playing } \\
\text { (reading) }\end{array}$ \\
\hline Formal methods & Statistics & Game ontologies \\
\hline
\end{tabular}

While the Humanities and the Social sciences both have formal and informal methods, it is in their empirical object that they differ most clearly: their conception of the player. For the social scientist, whether doing qualitative or quantitative research, the player is historical, situated, flesh and blood. For the humanist game scholar, whether engaged in close playing analysis of a single game, or trying to make sense of games as a complex, multifaceted medium with a huge repertoire of genres, the player is a necessary but uncontrollable part of the process of creating ludic meaning, 
a function that is created by the gameplay as well as cocreator of it. Given the origin of the text-oriented humanities as a discipline for the study of biblical meaning (exegesis), this abstracting of the reader should not be seen as a disregard for social reality, but as a means to govern interpretation. By positioning the ideal reader as a function of the text, the humanist is trying to exclude himself from the interpretation, while acknowledging that this is impossible. Thus, far from being ignored or glossed over, the problem of reading and interpretation is the central one in textual studies.

\section{THE IMPLIED PLAYER}

To solve the problem of textual meaning, the $20^{\text {th }}$ century literary theorist Wolfgang Iser [5] came up with a model termed "the implied reader". Iser argues that a literary text addresses an ideal reader, which "embodies all those predispositions necessary for a literary work to exercise its effect -predispositions laid down, not by an empirical outside reality, but by the text itself. Consequently, the implied reader as a concept has his roots firmly planted in the structure of the text; he is a construct and in no way to be identified with any real reader."

The notion of the implied reader has been applied to the field of games before; e.g. [1], p. 127, where I talk of the "implied user" in my discussion of adventure games. The implied player, then, can be seen as a role made for the player by the game, a set of expectations that the player must fulfill for the game to "exercise its effect". Following [1], we can come up with the following three-level model:

\begin{tabular}{|l|l|}
\hline Implied Player & \multirow{2}{*}{ The real, historical player } \\
\cline { 1 - 1 } Interface addresse & \\
\cline { 1 - 1 } Avatar/vehicle (if any) & \\
\hline
\end{tabular}

The game houses expectations for a player's behavior, which is supported by an interface, and represented in-game by an avatar (but not the latter in all games). Even more than the implied reader, the implied player has a concrete, material existence, because the game will not be realized unless some mechanism allows player input.

If we also link the notion of the implied player to Gadamer's notion of the unfree player subject, we can start to see the implied player as a boundary imposed on the player-subject by the game, a limitation to the playing person's freedom of movement and choice.

\section{YOU FOUND A SECRET AREA: THE TRANSGRESSIVE PLAYER}

While the implied player model is sufficient to understand the expectations laid down by the game for the player, it is not enough to explain real player behavior. Games are machines that sometimes allow their players to do unexpected things, often just because these actions are not explicitly forbidden. In other words, they are not part of the game's intended repertoire, and would in most cases have been rendered impossible if the game designers could have predicted them.

These moments of game transgression are nevertheless highly important to players, and in many cases celebrated as important events, or vilified as problematic and destructive. A list of such cases might include the famous heist in Eve Online, where a covert "assassin guild" killed the leader of a major in-game cooperation and stole its assets, worth many thousand dollars of real money. Another event is the death of Lord British in the beta trial version of Ultima Online in 1996: Rainz, a common player, managed, implausibly, to kill the game designer's supposedly immortal avatar, by using a fire spell that worked in a way it should not have. In Halo, a method called warthog jumping was discovered to propel player avatars high into the air, and thereby access unintended parts of the landscape.

All these moments, whether celebrated or derided as cheating, represents a transgression of the implied player. Transgressive play is a symbolic gesture of rebellion against the tyranny of the game, a (perhaps illusory) way for the played subject to regain their sense of identity and uniqueness through the mechanisms of the game itself.

\section{BREAKING THE LAW IN CRYODIIL: WONDROUS OBLIVION}

The Elder Scrolls IV: Oblivion(2006) is a particularly relevant but also challenging game to use in an analysis of player participation. Oblivion combines an open and persistent world, Cryodiil, with a fairly linear main quest: the player is invited, but not forced, to fight the evil spreading in the gameworld by closing a number of "Oblivion gates" - doorways to Hell. The world is geographically continuous and eminently detailed, consisting of one large level sprinkled with a large number of dungeons and caves, as well as towns, shops, inns, and treasures and hundreds of named non-playing characters (NPCs) and monsters of all kinds. The leveling and customization possibilities are overwhelming: New potions and weapons can be made by combining materials and spells, and the world can be explored for months of playing time. Given the complexity of both the world simulation and the sheer number of combinable elements in it, the possibility for unlikely and curious events are a great source of player entertainment. This potential for player creativity is supplemented by the usual exploitable bugs that inevitably plague such complex software projects.

At one time of playing, I was exploring the hills northwest of the central city, when I came across two foresters of the imperial army who were engaged in a bow and arrow duel, to the death. They simply kept firing, no 
explanation given, until one of them was killed. I have no idea what could have caused this animosity, and I had no way to find out.

There was no indication that this was a scripted event, and probably some small coincidence, such as one of them hitting the other by mistake while trying to kill a wild animal, had caused the fight to break out, but who knows. Later, as I was climbing a steep hillside to get into a mine, a wolf charged me jumping from above, but missed, hit some rocks further down, and died.

One of the more memorable exploits in the game is the item duplication trick, which allows players to create hundreds of copies of an item in-game. A movie posted to google [2] shows an avatar on a rooftop preparing to fire an arrow, stopping and changing the arrow to a large watermelon in the inventory screen and as the arrow/melon is then fired, it turns into several hundred watermelons, filling up the nearby area. This ridiculous spectacle is then made even more absurd by an NPC that comes walking by, completely ignoring the flow of melons, while greeting the avatar with a calm "Oh, Hello".

My own most hilarious moment in the game was when I got into a fight with the annoying and arrogant Captain of the City Watch, Hieronymus Lex. He is an imposing figure, in silver armor and a huge silver sword. I had finally managed to enter the Arcane University as part of the mage quest line, and consequently the mage scholars there became my friends and allies.

Also patrolling the area are the battle mages, a different faction employed as peacekeepers by the City. Somehow, while trespassing I managed to draw their unfriendly attention and so I was attacked by a small group of them in the Arcane University grounds. Hieronymus Lex was also there, and joined the fight with his usual cold persistence. My friends the mage scholars, however, are not cowards when it comes to defending their own. A wild battle broke out, and I managed to stay alive while the spells and swords flashed and bodies started to litter the ground. Even Lex got his comeuppance, and was knocked out by the sturdy scholars. Seizing my chance, I grabbed his sword lying on the ground beside him. In Oblivion, important NPCs can't be killed before they are supposed to, so Captain Lex was not dead, only unconscious. After a few moments he got up, picked up a little green magic dagger from one of my dead friends, and continued the fight. Luckily, the scholars carried the day, leaving me with some very nice loot, including the sword that I later sold to my fence in the Thieves Guild. I also paid a bribe to get me off the Cryodiil's-most-wanted list. Now, whenever I happen to meet Captain Lex in the street, I get a huge kick out of seeing him prancing around, fiercely ignoring my presence, while carrying a little green dagger.

\section{CONCLUSION}

These anecdotes, while not typical of the events a player will encounter in a game like Oblivion, nor representative of my own play experience in that game, are nevertheless among the most important aspects of play and gaming. The unexpected happening, the lucky shot, the brilliant move, the last-minute goal, the $99.99 \%$ unlikely drop of an epic item, the completely ridiculous situation produced by a software bug, are not incidental to gaming, but a vital part of the play experience. They may not happen all that often, but they are necessary as a counterweight to the implied player position, the prison-house of regulated play. If we look beyond normal, everyday computer gameplay, and take a look at sports, competitive gaming of all kinds, and phenomena like gambling, it is the unique event, the brilliant innovative player, the exceptional team among so many, that is celebrated and remembered by our culture. The unique, against-all-odds play event is what players live for, as they carry out their rather meaningless, repetitive tasks in the service of the game. While it is important to be aware of what players actually do, we cannot ignore this marginal phenomenon when trying to explain why they do it.

The games rule us. We as players are only halfourselves when we play, the rest of us is temporarily possessed by the implied player. These marginal events and occurrences, these wondrous acts of transgression, are absolutely vital because they give us hope, true or false; they remind us that it is possible to regain control, however briefly, to dominate that which dominates us so completely.

\section{REFERENCES}

[1] Aarseth, Espen 1997. Cybertext: Perspectives on Ergodic Literature. Baltimore and London: Johns Hopkins University Press.

[2] Bethesda Softworks 2006. Oblivion: Melons. http://video.google.com/videoplay?docid=8960256 445634741451

[3] Eco, Umberto 1979. The Role of the Reader: Explorations in the Semiotics of Texts. Bloomington: Indiana University Press.

[4] Gadamer, Hans-Georg 1989 [1960]. Truth and Method. London: Sheed \& Ward.

[5] Iser, Wolfgang 1974. The Implied Reader: Patterns of Communication in Prose Fiction from Bunyan to Beckett. Baltimore and London: Johns Hopkins University Press.

[6] Smith, Jonas Heide 2006. Plans And Purposes: How Videogame Goals Shape Player Behaviour. $\mathrm{PhD}$ dissertation. IT University of Copenhagen. http://jonassmith.dk/weblog/wpcontent/dissertation1-0.pdf 